\title{
MUJERES POBRES Y CUESTIÓN SOCIAL. BUENOS AIRES Y TUCUMÁN EN EPOCAS DE DESOCUPACIÓN
}

\author{
Cecilia CROSS ${ }^{1}$ \\ María ULLIVARRI ${ }^{2}$
}

\begin{abstract}
Resumen
El objetivo es analizar la producción de las mujeres pobres como sujetos sociales en dos momentos muy críticos de la historia argentina. Para abordar esta propuesta analizaremos lo que las mujeres hacían y decían para hacer frente al desempleo y las disputas de sentido acerca de esas prácticas, particularmente a partir de los discursos de los medios y las autoridades políticas acerca de quiénes eran y qué podían hacer (y decir) las mujeres pobres en los treinta y en los noventa. Nos centramos en Buenos Aires y Tucumán porque nos permiten ilustrar la heterogeneidad de situaciones sociales que se vivían en nuestro país, más allá de la homogeneidad de la crisis como escenario. Palabras clave: mujeres, desempleo, trabajo, Tucumán, Buenos Aires.
\end{abstract}

\begin{abstract}
The aim of this paper is to analyze the production of poor women as social subjects in two very critical moments in the history of Argentina, the thirties and the nineties. To address this proposal we will analyze what women did and said and the disputes on the social and political's meaning of that practices, specially with media and political authorities. Concerning geographic scope, we have chosen Tucuman and Buenos Aires because they represent the heterogeneity on our economy structure, within the homogeneity of crisis
\end{abstract}

\section{${ }^{1}$ CITRA/ CONICET - \\ CE: crosscecilia@gmail.com}

${ }^{2}$ CEIL/CONICET

CE:ulliva@gmail.com

Fecha de recepción del artículo: Febrero 2015

Fecha de evaluación: Mayo 2015 
Key words: women, unemployment, work, Tucuman, Buenos Aires.

Résumé

L'objectifestd'analyser la production des femmes pauvrescomme des sujetssociaux en deux moments très critiques dansl'histoire de l'Argentine. Pour répondre à cette proposition d'analyserceque les femmes ont fait et dit à luttercontre le chômage et les conflitsdétectersurcespratiques, en particulier après les discours des médias et des autoritéspolitiquessur qui ilsétaient et cequ'ilspourraient faire (et dire) les femmes pauvresdans la trente et quatre-vingt dix. Nous nous concentrons sur Buenos Aires etTucuman, car ils nous permettent d'illustrer l'hétérogénéité des situations sociales qui vivaient dans notre pays, au-delà de l'homogénéité de la phase de crise.

Mots-clés: les femmes, le chômage, le travail, Tucuman, Buenos Aires.

\section{Introducción}

El objetivo de este artículo es analizar la producción de las mujeres pobres como sujetos sociales, estudiando las disputas por el sentido de sus prácticas cotidianas en dos momentos muy críticos de la historia argentina, la crisis de los años treinta y la caída del régimen de convertibilidad a principios de los años 2000. Nos interesa visibilizar, a partir de un contrapunto entre los discursos "desde arriba" planteados por la cuestión social, el "desde abajo" que implicóel lugar de las mujeres en escenarios de falta de empleo. Para abordar esta propuesta analizaremos los discursos circulantes respecto a las obligaciones, responsabilidades y derechos de las mujeres pobres en cada una de estas etapas, como modo de acceder a su producción como sujetos sociales. Por otro lado, también nos detendremos en sus prácticas y en sus espacios de circulación, para aproximarnos a la construcción de esos lugares de resistencia femenina que constituyeron o dieron forma al sentido de la propia movilización.

Los estudiosos de la cuestión social en Francia señalan que a partir de los años treinta del silgo XX, el desempleo se incorporó como atributo distintivo al pauperismo, que había sido la principal cuestión social en el siglo XIX. En un contexto en el que el empleo era pensado como sustrato del orden social, el desempleo se convirtió en un aspecto que era necesario corregir desde la política pública (Gautié, 2001). La sociedad salarial así definida se caracterizó por promover políticas de distribución de la "propiedad diferida" (Castel, 1997) a través del empleo, que se presentaron generalmente como de carácter "universal", señalando su carácter impersonal y extendido, dado que alcanzaban a todas las personas que cumplieran con las condiciones que definían a la población beneficiaria y mientras perdurara la relación salarial. De este modo, como expresión de la vocación hegemónica de las clases dominantes, el status contractual de los/as trabajadores/as se convirtió en la llave de acceso a las políticas de integración y ciudadanía, moldeando el perfil de la cuestión social en términos de desempleo, en la medida que delimitaban la relación salarial como "lo deseable" (Rosanvallon, 1995; Castel, 1997). En este contexto, las dificultades del desempleo fueron atribuidas, la mayoría de las veces a la irracionalidad de las prácticas de los/as trabajadores/as y a su escasa disciplina y sentido del deber. No obstante se esperaba que estado y empresas pudieran moldear a esta fuerza de trabajo para alcanzar la meta del pleno empleo (Castel, 1997; Romo Parra, 2005). Esta conceptualización entró en crisis al resquebrajarse el lugar del pleno empleo como meta organizadora de la política social (Castel y Haroche, 2001). 
En una línea similar, en Argentina de los años treinta el empleo también comenzaba a constituirse como un factor central de integración social y se comenzaron a sentar las bases de algunas políticas que terminarían de cuajar con el peronismo. Pero el mercado de trabajo se consolidó como factor explicativo del desempleo y hubo quienes intentaron explicar la desocupación como producto de la inadecuada distribución geográfica de la fuerza de trabajo(Girbal, 2003, Ullivarri, 2006). ${ }^{3}$

A partir de los años noventa la deconstrucción del desempleo como cuestión social (cfr. Rosanvallon, 1995; Castel,1997, Gautié, 2001) dio a luz a un nuevo concepto con el que explicar el déficit de integración social de un creciente número de trabajadores/as de diferentes latitudes: la vulnerabilidad social entendida como inempleabilidad. Este concepto se presentó indisociablemente arraigado en atributo personalísimos de quienes no accedían al empleo formal: su condición de género, su trayectoria laboral, la cantidad de hijos/as asu cargo, el nivel de instrucción alcanzando, entre otros aspectos. Estos aspectos explicarían porque tal o cual sujeto en particular noes elegible para un empleo.Así, de la mano de esta peculiar lectura de los conceptos de capital social y humano (cfr. Cross 2013; Formichella y London, et al. 2013) la vulnerabilidad no es ya entendida como producto de la marginación de un conjunto de trabajadores/as del mercado de trabajo, sino como causa, invirtiendo el argumento tradicional: los/as trabajadores/as no son vulnerables a la pobreza porque están desempleados/as (o precarizados/as), sino que están sin trabajo (o acceden a un trabajo precario) porque son inempleables, y esa inempleabilidad es el sustrato de su vulnerabilidad social, argumento que deja fuera del debate las estrategias precarizantes del capital.Por otra parte, esta definición de la cuestión social llevó a una reformulación en la lógica de intervención estatal, del esquema universal-impersonal que se fue consolidando durante el siglo XX, al focalizado-personalizado, esquema que por lo demás ofrece una visión bastante peculiarde la vulnerabilidad social al colocarla condición de género y la cantidad de hijos/as (de las mujeres) como atributo de empleabilidad (Aspiazu, 2013, Baker, Collins, 2005; Cross, 2013).

Frente a esta caracterización nuestra pregunta es ¿qué significó para las mujeres pobres cada una de estas formas de plantear la cuestión social? ¿qué hicieron frente a las dificultades económicas que afectaban a sus hogares? ¿qué se dijo sobre lo que hacían? ¿qué decían ellas que estaban haciendo?En la literatura de referencia sobre los cambios en la definición de la cuestión social las relaciones de género no son presentadas como un aspecto relevante. Sin embargo, existen miradas que señalan los años treinta y los noventa como momentos en que las mujeres fueron protagonistas de la conflictividad social y las resistencias asociadas al deterioro de las condiciones de vida de los sectores populares (Tuccio, 2002, Andújar, 2007, Cross y Freytes Frey,et al.2007). A partir de estos nuevos aportes y teniendo en cuenta que la definición de la cuestión social es un modo de acceder a los límites - materiales y simbólicos- de la ciudadanización de las mujeres, nuestra propuesta en analizar, desde un prisma de género, esas definiciones en dos momentos críticos en nuestro país: la crisis de los años treinta y la caída del régimen

\footnotetext{
${ }^{3}$ Más allá de lo acertada que pudiera ser o no esta afirmación técnicamente hablando, nos importa resaltar que el solo hecho de que pareciera razonable sostener que era responsabilidad de las personas desocupadas comportarse como agentes económicamente racionales y establecer su lugar de residencia en función de la "oferta" laboral, por lo demás escasa e insuficiente, da cuenta de la eficacia performativa del concepto de mercado de trabajo.
} 
de convertibilidad, para mirar allí las estrategias de (y para) las mujeres pobres en épocas de crisis. ${ }^{4}$

\section{Crisis y desocupación. Las mujeres que eran invisibles}

Una de las consecuencias más drásticas de la crisis capitalista mundial de 1929 fue la caída de las tasas de empleo que llegaron a su punto más bajo en 1932. Ese mismo año se realizó el primer censo de desocupados del la historia del país. Se contabilizaron 333.997 parados en todo el territorio nacional, de los cuales el 5,5\%, o sea 16.699 trabajadoras eran mujeres. Los porcentajes más altos de desocupación se encontraban en la provincia de Buenos Aires (26,60\%) y la Capital Federal (26,15\%), mientras que el más bajo se registró en Tucumán, con un $0,69 \%$.

El problema de la desocupación, aunque había existido siempre en el país y había tenido picos altos como en 1913, nunca había alcanzado las magnitudes de los primeros años treinta. O por lo menos esas magnitudes no habían sido contabilizadas con anterioridad. En ese esfuerzo la cifra estadística comenzó a tener importancia pública, consolidando al primer paso hacia la puesta en agenda de la cuestión social en clave de desempleo y como el principal elemento de justificación, tanto científica como política, para la ampliación de los márgenes de la política social del Estado (Daniel, 2013). En ese sentido, con los datos oficiales el paro ya nada tenía que ver con la mera "percepción de los afectados" (Daniel, 2009:16) como se venía registrando en algunos discursos públicos hasta ese entonces.

Sin embargo, a pesar de la contundencia del número, estaba en el aire la sensación de que las cifras no reflejaban del todo la realidad. Las crónicas, la prensa, el arte, y las impresiones cotidianas parecían reflejar un impacto mayor. En el caso de Tucumán se estimaba que en realidad esa cifra era "una ínfima expresión de la verdad" (La Gaceta 24/08/1932). ${ }^{5}$ Lo mismo decía el diputado Pérez Leirós en el Congreso, respecto a la ciudad de Buenos Aires "las cifras [...] están muy por debajo de la realidad." Así, los grupos de izquierda mayormente, salieron a proponer cifras tanto mayores a fin de imponer una realidad más compleja que la oficial (Iñigo Carrera y Fernández, 2011). ${ }^{7}$

En 1934 se alegó que el país había salido de la crisis, pero poco tiempo después, la creación de la Junta Nacional para Combatir la Desocupación (JUNALD), como órgano dirigido a formular políticas públicas tendientes a mitigar los efectos del paro, refutó los discursos más optimistas sobre la magnitud del problema. La JUNALD fue una de las medidas más importantes que tomó el gobierno para disminuir la desocupación porque aunque circulaban proyectos para crear un seguro de desempleo o para reducir la jornada laboral, el gobierno constitucional de Agustín P. Justo hizo poco por paliar la situación de los "harapientos". Incluso la CGT denunciaba que la única política oficial era permitir que los desocupados acamparan en Puerto Nuevo (CGT, 25/07/1933), mientras que, por su parte, los anarquistas indicaron los maltratos policiales y el

\footnotetext{
${ }^{4}$ Este trabajo se basa en los resultados de investigaciones sociológicas e historiográficas desarrolladas desde 2003, que tienen continuidad a la fecha con apoyo del FONCyT y el CONICET.

${ }^{5}$ Departamento Nacional de Trabajo, División Estadística, La desocupación en la Argentina, 1940, Buenos Aires, 1940, Departamento Nacional del Trabajo, Boletín Mensual, Buenos Aires, Noviembre de 1932.

${ }^{6}$ Honorable Cámara de Diputados de la Nación, Diario de Sesiones, 1933, Tomo II, p. 932.

${ }^{7}$ Ciertamente el Poder Ejecutivo parecía desestimar la gravedad de la situación señalando que los desocupados eran solo el 2,4\% de la población total del país (Panettieri, 2000:26).Entérminos estadísticos modernos el desempleo correspondía a casi el 28\% de la PEA (Korol, 2001).
} 
incendio de los asentamientos de desocupados (La Protesta; 29/04/1932). Si bien estas proclamas exageraban la inacción gubernamental, es cierto que las ideas del gobierno se acotaban a "organizar y fomentar el desarrollo del trabajo (en tanto) el Estado no debía mantener a los desocupados, sino administrarles el medio de ganarse sus sustento" (Panettieri, 1997: 49).

La actitud gubernamental frente a la desocupación como problema revela varias de las sendas explicativas que tomaron las interpretaciones sobre las causas del paro. El principal diagnóstico se centró en el desequilibrio entre los lugares de la oferta y los de la demanda. Pero también se sugería que la desocupación rural y urbana podría corresponderse con la presencia de inmigrantes desocupados en busca de mejor suerte, los progresos mecánicos, las sequías y la langosta, la acumulación de empleos, el trabajo de los jubilados, la sobrepoblación obrera en las ciudades y también el trabajo de la mujer que "sustituye al hombre por un salario más bajo."En este concierto de voces, podían escucharse esporádicamente versiones como la del diputado socialista Nicolás Repetto, que informaba a la OIT que la causa de la desocupación era "la economía de la mano de obra que se hace en las chacras y al empleo creciente de los medios mecánicos en la agricultura"(CGT, 14/09/1934). El socialista ponía su mirada en las prácticas de racionalización para desarmar los discursos hegemónicos que culpabilizaban a los trabajadores. Y algo similar hacía la CGT, que atribuyó la desocupación a la "insuficiencia del consumo", debida a los bajos salarios, a la incorporación de maquinaria, y a "la propiedad capitalista de los medios de producción" (Boletín CGT, 15/1/1932 y25/10/1932).

Las disputa por imponer una interpretación sobre las causas del desempleo era sin duda un espacio concurrido, pero en ese campo de fuerzas, y especialmente si juzgamos las políticas llevadas adelante, podemos sospechar que el discurso hegemónico centrado en los problemas de la oferta perfiló el grueso de las medidas tomadas para darle una solución al problema y construyó al trabajador y a la trabajadora como responsable de su situación. El paquete de medidas políticas tomadas para paliar el desempleo estuvo acotado a los problemas de traslado de mano de obra que respondían a las características del modelo productivo nacional, fundamentalmente agropecuario, donde si la "demanda de brazos fluctúa en forma periódica, sería suficiente [...] la traslación de hombres para facilitar la nivelación de la oferta y la demanda" (Girbal, 2003:32).

En el plano cotidiano, sin embargo, la pobreza y la miseria se instalaron quebrando las prácticas y los usos populares del tiempo libre, el ocio y el trabajo y las formas de estar, vivir y sentir resultaron desarticuladas frente a la inmediatez de la supervivencia. El hambre comenzó a volverse una lectura cotidiana que promovió nuevas formas de defensa colectiva. El saqueo, tanto en Buenos Aires como en Tucumán funcionó como una forma espasmódica de resistencia. Las crónicas tucumanas relataban que la "horda" penetró en esos establecimientos "para destruir hasta a los puestos", y que algunos robaban mercadería mientras otros "sembraban el suelo y la calle de frutas, pesas, balanzas, etc." (La Gaceta, 04/02/1932). En Buenos Aires y Tucumán la proliferación de asentamientos empezó a modificar el paisaje visibilizando sectores sociales de cuya existencia nadie parecía haber tomado nota antes. La presencia de "los parias y marginados" sin trabajo era indisimulable.

Estaba claro que el trabajo y la supervivencia eran las discusiones cotidianas y en este escenario fue donde las mujeres adquirieron notable protagonismo ¿Qué sucedió con ellas en un contexto tan hostil? Hay ciertamente algo de inasible en las trayectorias de las mujeres. Constantemente invisibilizadas, intentar reconstruir sus itinerarios obliga a 
leer entre líneas, a buscarlas en los intersticios de una historia donde su ciudadanía era sumamente acotada. Las crónicas incluso relatan que muchos asentamientos de desocupados, como Villa Desocupación eran solo habitados por hombres (Iñigo Carrera y Fernández, 2011: 27) que esperaban algún trabajo o ser desalojados ¿Dónde estaban las mujeres?

Desde el Estado o desde sus funcionarios, la posibilidad de que las mujeres trabajaran y salieran del espacio doméstico configuraba una alternativa perturbadora. La JUNALD reprodujo (o institucionalizó) los discursos circulantes acerca de las mujeres pobres. Así, la Junta señaló varias veces que consideraba "el trabajo de la mujer como factor de desocupación masculina", pero no solo porque "sustituye al hombre por un salario más bajo", sino porque su presencia pública es un "pernicioso influjo en la familia, al alejarla del hogar". 8 A través de la JUNALD también la Federación Agraria explicó que consideraba al trabajo femenino como competitivo del masculino, y afirmaba que es más grave aún en el caso de la labor en el campo por ser "impropios para el género femenino" (Girbal, 2003). Ya que "esos trabajos generan enfermedades y perjuicios en el físico de las mujeres y una procreación raquítica y aún deforme. Que por estas razones, la promiscuidad y la falta de higiene perturba peligrosamente la moral, con derivaciones sociales temibles: las ideas políticas exóticas y la mendicidad descarada y rebelde son las primeras revelaciones." En esa misma línea de pensamiento la Iglesia señalaba al trabajo de la mujer "como causa determinante de desmoralización social, en cuanto desintegra y obstaculiza la vida regular de la familia. Las entidades que se preocuparon por nuestro régimen doméstico destacaron la influencia perniciosa del trabajo de la mujer, que la obligaba a desentenderse de sus ocupaciones naturales en el seno del hogar" (Acha, 2000:68). A partir de este concierto de ideas y en un escenario de desempleo, la campaña para lograr que la mujer vuelva al hogar se intensificó. "Aceptada la influencia de la ocupación femenina en el problema del paro forzoso, corresponde concretar con dura franqueza la necesidad de que la mujer retorne al hogar, para que cese esa especie de matriarcado impuesto, que uno y otro sexo admiten con biológica antipatía." 10 Diariamente se reproducían estos discursos que afirmaban también que "esta desocupación no es el producto de una restricción de las actividades de esas empresas solamente, sino también de la sustitución de la mano de obra masculina por la femenina." Así, La Gaceta (28/06/40) señalaba que era necesario reflotar "el papel hogareño de la mujer, sobre todo cuando es madre de familia. Sólo así se solucionará el angustioso problema de la desocupación".

Mientras nadie parecía cuestionar el funcionamiento del mercado de trabajo ni mucho menos el sistema económico, parecía consolidarse algo del orden de la culpabilidad femenina en las declaraciones de funcionarios, agencias estatales, organizaciones civiles y en la misma prensa. Las mujeres aunque eran el "grupo con más alto índice de desocupación"11, estaban expuestas a mayores riesgos y eran el colectivo más vulnerable, fueron acusadas de abandonar sus roles domésticos, particularmente el cuidado de los/as hijos/as y contribuir al deterioro del posicionamiento de los varones en el mercado de trabajo. Estos eran "límites morales" a la ciudadanización de las mujeres, en tanto la posición virtuosa y deseada, el empleo, estaba asociada a los

\footnotetext{
${ }^{8}$ Junta Nacional para Combatir la Desocupación (1938) Memoria 1937, Buenos Aires, p. 26

${ }^{9}$ Ibidem, p. 28

${ }^{10}$ Ibidem, pp. 69-70

${ }^{11}$ Departamento Nacional Del Trabajo; Investigaciones Sociales; Buenos Aires, 1940.
} 
hombres y era una fuente de muchos conflictos sociales (inmediatos y potenciales) para las mujeres. De esta forma, en un escenario donde el trabajo se convertía en el garante de la inclusión, las mujeres intentaban ser excluidas justificándose en una dicotomía imaginaria (público/privado) que organizaba los sistemas sociales y se establecía normas que definían espacios de competencia para las actividades económicas, políticas y culturales de las mujeres (Armstrong, 1991).

Cuando la familia dejó de ser el eje de la producción para convertirse mayormente en una unidad emotiva, se crearon dos mundos separados: la "familia" y el "trabajo", dividiendo la sociedad en dos esferas de acción: la pública y la privada (Lobato, 2008). Esta separación ha sido cuestionada (Fraser y Gordon, 1992, Jelin, 1984). Lobato (2008), por ejemplo, propone un análisis sensible a las tensiones entre trabajo productivo y reproductivo, especialmente para romper con la visión dicotómica presencia/ausencia de las mujeres en la acción colectiva y en el trabajo. La idea es poder revelar que las mujeres bregaban por la subsistencia de sus hogares y compartían el espacio público con los hombres a través de lugares de trabajo, pero también a través de huelgas, manifestaciones y enfrentamientos con la policía.

Sin embargo, donde mayor visibilidad adquirieron las mujeres fue en los discursos obreros. Allí las "mujeres proletarias" sirvieron para representar el lado más oscuro de la desocupación, de la vida proletaria y de la miseria. Por eso los dirigentes varones solían invitarlas a los mítines junto con los niños, donde a pesar de su condición de desocupadas o de luchadoras, la intención de mostrarlas a la sociedad poniendo en juego un sistema de valores pretendidamente universal donde las ellas debían ser protegidas. ${ }^{12}$ Así se intentaba "demostrar a los ricos que mientras ellos viven en hogares entre el lujo y la abundancia, hay un pueblo que sufre hambre, que hay madres proletarias semidesnudas, que hay niños débiles, que agonizan y mueren en los brazos de las madres proletarias en la miseria, sin atención médica y sin los remedios indispensables para su curación. Y que a pesar de que se combate el analfabetismo hay miles de niños que no pueden concurrir a las escuelas por la falta de guardapolvos blanco y los botines que exijen (sic) en las escuelas. Todo por las consecuencias de la desocupación obrera." (La Gaceta, 05/04/1931).

Paralelamente, tal como el Estado y la prensa, dentro de la propia retórica obrera sobre el desempleo también se las culpaba de ocupar puestos de trabajo perjudicando al hombre, pero en los discursos de crisis no se las nombraba más que como madres y compañeras. En ese sentido, Mirta Lobato (2007: 296) destacó que cuando los trabajadores se reunían, la presencia femenina era casi inexistente, "ella solo cobraba fuerza cuando se planteaba como necesidad narrativa mostrar la brutalidad del sistema capitalista."

De esta manera, aunque trabajadoras por la supervivencia y protagonistas de las manifestaciones, los conflictos y la lucha, los oradores rescataban una esencia femenina reducida a la procreación y a partir de la cual se derivaban sus deseos, aspiraciones y experiencias. En un contexto de crisis, esas ficticias, pero tajantes divisiones entre lo privado y lo público se volvían más porosas. Esto se pone de manifiesto más claramente en ese espacio fronterizo que emerge contundente durante las crisis que es la lucha por

\footnotetext{
${ }^{12}$ Daniel James (2006) expresa que el tema de la amenaza a las obreras, y la necesidad de proteger a las mujeres era un tema recurrente de la cultura popular y, en este sentido, su ubicación como principal víctima de la miseria reflotaba la necesidad de protegerlas y daba impulso y legitimidad a la lucha.
} 
la subsistencia, la supervivencia del hogar, porque si bien la manutención estaba a cargo de los hombres, su integridad corría por cuenta de las mujeres.

Los nuevos estudios han propuesto formas más completas de análisis social que integran los espacios domésticos a los públicos (Taylor 2014). En ese sentido, entendemos que en esos espacios fronterizos se pueden pensar a las mujeres en la acción, con sus propias formas de estar y de luchar. En tal sentido, puede decirse que el lugar de las mujeres como garantes de la reproducción del hogar (y no como meras proveedoras) las coloca en un rol difícil de asir desde la separación tajante entre trabajo público remunerado y trabajo privado no remunerado. En tiempos de crisis se observa además la diversificación de las estrategias para acceder a recursos, entre las cuales las transacciones monetarias en el mercado conservan un lugar central, pero no son la única posibilidad. Esto nos coloca frente a la necesidad de recuperar enfoques que desnaturalicen la correspondencia entre trabajo y remuneración (Taylor, 2014) según la cual el trabajo siempre implica la venta de la fuerza de trabajo Glucksmann (1995). En cambio, resulta necesario partir de la continuidad (y no de la ruptura) entre el trabajo productivo y reproductivo, campo del interés y del desinterés, sector formal e informal.En escenarios conflictivos o de crisis, donde las prácticas y los sentidos estaban en permanente redefinición, los espacios públicos y privados aparecían aún más fuertemente entrelazados y otorgaban a las mujeres un rol fundamental. Protagonistas casi innegables cuando de supervivencia se trataba, y casi símbolos de ese problema, suelen llamarse (Kaplan, 1990) y ser también llamadas a la acción.

No hay dudas de que la crisis y la desocupación convirtieron las carencias de la vida cotidiana en un asunto público y la defensa del hogar obrero fue la consigna más importante de la época. Sobre espacios que habían sido delimitados culturalmente, correspondía a las mujeres defender sus hogares o por lo menos garantizar su supervivencia. Así lo explicaba una obrera fideera despedida en Tucumán: "Usted debe comprender, señor, que si trabajamos es porque la necesidad nos arrebata del hogar para entregarnos a la lucha por la vida", de decía Florencia Jiménez al cronista del diario El Orden (16/04/1931). Esta oposición entre quedarse en el hogar o luchar por la vida muestra como los estereotipos de género ordenan y hacen posible el entendimiento pero no son necesariamente un límite infranqueable entre los espacios abiertos/clausurados a las mujeres. Florencia acepta que su lugar es el hogar, pero también convoca a comprender su inserción laboral como un recurso desesperado, y en tal sentido, como un deber moral de mayor al respeto de la tradición, la lucha por la subsistencia. Y fue más allá, porque reclamó un mejor salario, y esa fue la causa de su despido.

En Buenos Aires también se registraron episodios de lucha e incluso detenciones de mujeres que protestaban contra la desocupación (La Internacional, 12/1930). Y también muchas mujeres salieron a luchar a través de disputas por el consumo que constituye un proceso social de apropiación de ciertos productos y está, por ello mismo, íntimamente vinculado con las disputas por la distribución de la riqueza. Por ello, en determinadas circunstancias históricas, el consumo es el lugar donde los conflictos entre las clases pueden manifestarse más claramente. De este modo, las protestas individuales y colectivas contra la carestía encabezadas por mujeres se configuraron como parte y consecuencia de una estrategia de lucha y de extensión de los espacios y límites impuestos por los roles de género.

En ese mismo sentido, la acción de las mujeres se extendió también hacia la búsqueda de refugio en estrategias autogestionadas que, en algún punto, formaron un híbrido entre los espacios de interacción social/barrial y las esfera laboral y doméstica en las que las 
mujeres actuaban con soltura. Porque como publicaba el semanario de la CGT el Estado no ayuda a los trabajadores sin empleo, y "los socorros "estatutarios" $\mathrm{u}$ otras formas de ayuda en caso de paro solo existen para una mínima fracción de los asalariados argentinos" porque solo algunas organizaciones han logrado "poner en pie una asistencia regular a costa de sacrificios considerables" (CGT, 20/09/1935). En los treinta las mutuales, las organizaciones comunitarias, los centros barriales, las cooperativas y los círculos de obreros se construyeron como lugares de supervivencia y solidaridad. Mientras que, por su parte, apareció un fenómeno novedoso, la organización gremial de los desocupados, principalmente de la mano de aquellos dirigentes con simpatías con el comunismo (Ullivarri, 2006). Esos espacios de autogestión podían organizar compras, brindar comida, proponer espacios de entretenimiento o fomentar la solidaridad. Algunas de estas sociedades también trabajaban con las "damas de beneficencia" para manejar comedores para desocupados.

Frente a las pesadas representaciones que limitaban sus anhelos, las mujeres no dejaron de intentar resignificar ese lugar asignado. Independientemente del uso público y discursivo de su imagen, las mujeres, al demandar, al trabajar, al colaborar, al recurrir a los actos públicos dieron a su presencia y sus acciones un sentido político que comenzó a quebrar su exclusivismo doméstico. Esas intervenciones también fueron de acción directa y se pueden rastrear en el número de detenidas en conflictos de la rama del vestido, donde en términos generales, las mujeres estaban sobrerrepresentadas respecto a otras ramas, en ciertos puestos dirigenciales en sindicatos, en congresos de la CGT donde protestaban por la falta de consideración de la central sindical hacia las mujeres trabajadoras, etc, (Ullivarri, 2012; CGT, 01/01/1937). Allíalgunas mujeres apelaron a un discurso de clase convirtiendo el lenguaje de género en un modo de expresar las intervenciones de clase (Acha y D'Antonio, 2000) donde ser madre no se contraponía necesariamente con la lucha ni la domesticidad con el espacio público.

Pero esa participación, sin embargo, no se hacía sin sacrificios porque aunque luchadoras, las mujeres seguían siendo el eje de sus hogares. Las posibilidades de su actividad extradoméstica se veían muchas veces limitadas por las horas debidas al cuidado de los hijos y siempre dificultaba su actuación "plena". Sin embargo, pensar esa plenitud obliga a discutir los diferentes espacios donde construían resistencias y defendían sus derechos yexige desarmar falsas dicotomías y ampliar la mirada sobre el mundo obrero y popular. En ese sentido, historiadoras feministas reclamaron la necesidad de abordar los complejos senderos de constitución de la clase obrera destacando la heterogeneidad de la experiencia y del proceso de formación de clase (Scott, 2009; Taylor 1983), desarticulando las miradas normalizadoras (o fundacionistas). Esto implica pensar a las mujeres desde sus diferentes maneras de entablar demandas, destacando, a la vez, la construcción de amplios universos de sentido, incluso adentro del hogar, abriendo así el juego para la problematización de la compleja experiencia obrera.

Estas revisiones fundamentales permiten ampliar el campo de estudio sobre el conflicto y extenderlo hasta los espacios más olvidados de la vida de las trabajadoras. En esos procesos las mujeres dejaron huellas de sus sutiles coincidencias, de los reclamos comunes (masculinos) que de forma no siempre explícita y no siempre ordenada, construyeron las aspiraciones generales de los sectores populares en el sentido de derechos, reconocimiento, legitimidad e intereses. Pero, fundamentalmente, aparecieron allí los sentidos identitarios, los objetivos y los deseos de las trabajadoras, como mujeres y como obreras. 


\section{La nueva cuestión social en la Argentina a fines de los 90}

Como en buena parte de los países latinoamericanos, a partir de mediados de los setenta, Argentina fue escenario de un proceso de reformas que pusieron en juego los soportes de la ciudadanía social construidos en las décadas precedentes. Estas políticas repercutieron notablemente en la estructura productiva del país y, por consiguiente, en la calidad de vida de los/as trabajadores/as asalariados/as, muchos/as de los/as cuales perdieron su empleo y/o vieron deterioradas sus condiciones de contratación, profundizándose a lo largo de los años noventa.

Sin embargo, el aumento del desempleo fue interpretado en los primeros años de la convertibilidad como producto del aumento de la demanda de trabajo. Según esta interpretación entre 1991 y 1993 el empleo estuvo signado por dos fuerzas de sentido opuesto: por un lado la expansión económica habría favorecido la creación de puestos de trabajo en una economía que había atravesado una fuerte etapa de estancamiento. Por otro, el aumento en la productividad (sobre todo en el sector servicios) y la reestructuración estatal tendieron a reducir la elasticidad de la relación empleoproducto. Considerando este escenario, es posible ver que la precarización y/o el desempleo que afectó a los/as jefes de hogar llevó a que integrantes de los hogares hasta entonces inactivos/as comenzaran a buscar empleo para compensar la pérdida o reducción de los ingresos.

En Tucumán, en cambio, la estructura productiva sufrió un proceso de primarización, agravado por la crisis de la industria azucarera. Por otra parte, si bien se desarrollaron otros sectores agroindustriales, como la soja o el limón, éstos acentuaron la especialización territorial, funcionando casi como enclaves en un marco de inserción de la economía tucumana en el mercado internacional (Rivas y Hernández, 2012), con baja demanda de mano de obra calificada o permanente y predominando la contratación en negro y el pago a destajo. Si tenemos en cuenta que la encuesta permanente de hogares toma sus mediciones en contextos urbanos, estos datos nos dan una pauta acerca de la caída en la tasa de actividad, mientras que el último censo registra un incremento en la población rural en la provincia. Estas tendencias se explican por el aumento de las pequeñas explotaciones agrícolas familiares caracterizadas por su baja capitalización y la explotación de la mano de obra familiar y el incremento del desempleo, generando en ambos casos dependencia de los programas sociales asistenciales del estado.

En este marco es posible observar que la desestructuración del mundo obrero comenzada en los sesenta con el cierre de 11 de los 27 ingenios que funcionaban en la provincia y acentuada en los noventa ha tenido efectos profundos y duraderos, pues ni siquiera la recepción de inversiones o el desarrollo de actividades orientadas al mercado internacional, como las asociadas al limón y la soja, impactó inmediatamente en los sectores postergados.

En ese escenario, las primeras manifestaciones de la redefinición de la cuestión social en términos de inempleabilidad se expresaron con la implementación de los programas Trabajar que entregaban un subsidio a cambio de una contraprestación laboral de cuatro horas. Si bien estos programas fueron diseñados para contener las puebladas en las localidades petroleras, el epicentro del conflicto por el desempleo se desplazó al conurbano bonaerense a partir de 1998, llegando a "nacionalizarse" a partir del 2000 (Cross y Freytes Frey, 2009). En este marco,un nuevo modo de protesta asociado al movimiento piquetero se expandió por las zonas urbanas de todas las provincias.

En diciembre de 2001, frente a la caída del gobierno nacional y el quiebre del programa neoliberal, las organizaciones piqueteras se había convertido en actores políticos 
relevantes y los programas sociales eran pensados como uno de los principales recursos de contención social. El $1^{\circ}$ de enero de 2002 el senador Eduardo Duhalde asumió en forma provisional la primera magistratura. Inmediatamente decretó la "emergencia económica, alimentaria y sanitaria" en el marco de la cual se instrumentó el "Programa Jefes y Jefas de Hogar Desocupados" (JYJHD), mediante el decreto del Poder Ejecutivo Nacional (Pen) $N^{\circ} 565 / 02$. Este programa pretendió tener alcance "universal" con la intención de revisar la lógica de "focalización" que había caracterizado a las políticas sociales de los noventa, aunque siguió funcionando bajo el esquemadel trabajo como único modo de participar en la distribución de la riqueza socialmente generada, a través de contraprestaciones. Sus potenciales beneficiarios/as fueron, en primera instancia, todos/as los/as jefes y jefas de hogar con hijos/as menores o discapacitados/as a su cargo o con cohabitante en estado de gravidez.

A pesar de que la "universalidad" no fue alcanzada, el programa llegó a tener casi dos millones de beneficiarios/as y se estima que el $8 \%$ de los "planes" fueron gestionados por organizaciones "piqueteras", lo cual constituyó un volumen de recursos realmente significativo (Fuente: MTESS). En las organizaciones la mayor parte del tiempo y el esfuerzo estaba concentrado en la gestión de los programas sociales. Habitualmente eran las mujeres las titulares del "plan", mientras los varones -en los hogares en que había alguno- buscaban changas.

La propuesta del "plan" fue desarmando la tradicional distribución de roles y espacios en función de la condición de género, ya que en este contexto el trabajo no respondía a la clásica división actividades remuneradas y no remuneradas ni a una delimitación tajante entre ámbito público y privado. En cambio podemos pensar en la existencia de un espacio barrial-comunitario y uno extra comunitario. En el primero se situaban tanto las actividades vinculadas a la crianza y atención de los/as hijos/as como a la realización de la contraprestación laboral que exigía la percepción del plan. Éstas generalmente consistían en prestar actividades comunitarias -en el comedor, en el ropero, de apoyo escolar-, o bien realizar actividades orientadas a la administración de los programas sociales o a la mejora en las condiciones de infraestructura del barrio. Así no era raro que las mujeres que cocinaban en el comedor comunitario contaran a sus propios/as hijos/as entre los/as comensales. Este ámbito estaba reservado principalmente a las mujeres y si bien la mayor parte de las actividades tenían lugar en las inmediaciones del hogar, existían algunas tareas que las llevaban "más allá del barrio" como las reuniones -con líderes o funcionarios/as- y las movilizaciones, marchas y piquetes, que a veces se prolongaban por varios días y hasta semanas.

Si bien no todas estas actividades estaban necesariamente monetizadas formaban parte de las obligaciones impuestas a las personas que percibían un "plan", por eso no pueden encuadrarse sencillamente en la división tajante entre actividades remuneradas y no remuneradas. En este marco, las changas -que se prestaban en el ámbito extracomunitario- solían aportar un ingreso de dinero mayor a la economía doméstica, pero no necesariamente más significativo dado su carácter esporádico y contingente. En este contexto, muchas mujeres vieron fortalecida su posición en el hogar dado que eran quienes garantizaban el aporte regular de recursos -dinero, alimentos, vestimenta, etc.con los que se garantizaba la reproducción (Cross y Freytes Frey, 2007)

A partir de 2003, bajo la gestión Kirchner, hubo importantes cambios en la política social. La primera medida fue "discontinuar" el JYJHD, para lo cual se dispuso el inmediato "congelamiento" de la nómina de "beneficiarios/as", prohibiendo registrar "altas", que redundó en una reducción de la cantidad de "beneficiarios/as". La segunda 
medida fue clasificar a la población "beneficiaria" del JYJHD en virtud de su "empleabilidad" y "voluntad de trabajar". Aquellos/as considerados/as como "empleables" recibirían capacitación para el trabajo y un subsidio fijo durante un máximo de dos años, en el marco de los cuales se esperaba su inserción en el empleo formal a través del mercado de trabajo (Art. $4^{\circ}$ del Decreto PEN No 1506/04). Fueron considerados como tales personas que acreditaban experiencia previa en el trabajo, preferentemente varones, que manifestaran su inmediata disponibilidad para comenzar en un empleo. En el marco de la misma estrategia de reconfiguración, el resto de los/as beneficiarios/as fueron "transferidos/as" a la órbita de injerencia del $\mathrm{MDS}^{13}$, donde irían siendo "incorporados/as" como "población vulnerable" a otros programas sociales diseñados ad hoc, según lo establecido en el mismo decreto.

Uno de las políticas "destinadas a "atender" a estos "grupos vulnerables" fue el "Programa Familias por la Inclusión Social", o "Plan Familias" (Decreto PEN 825/05). Este programa, dirigido principalmente a las mujeres jefas de hogar, asignaba un subsidio variable en función de la cantidad de hijos/as menores de 19 años a cargo de la persona beneficiaria, no exigiendo "contraprestación laboral", sino la acreditación de que los/as menores acudían a la escuela y estaban cumpliendo con el plan de vacunación. Así fue recibido por una líder barrial bonaerense:

El Familias te manda de vuelta a tu casa... y yo me la pasé 30 años adentro de mi casa y si ahora tengo que volver me siento asfixiada. Yo me puedo ocupar de vacunar a mi hijo y también del comedor... No sé que se creen. A mí no me importa por mí, porque nadie me va a impedir que me siga ocupando de las cosas de acá, pero por ahí otras compañeras se van a ir... Además si a mí no me hubieran obligado a salir de las 4 paredes de mi casa, todavía estaría ahí y pienso que la contraprestación era una cosa positiva para sacar a la mujer de su casa, de las ollas, del marido... Y también al desocupado, que por lo menos se tenía que vestir y peinar para ir a hacer la contraprestación, no estar todo el día tirado en la cama... Al final parece que te quieren incentivar la chatura, la vagancia, no sé.

Las críticas al programa Familias se relacionan en este caso con la función de socialización en "la cultura del trabajo" que muchos dirigentes piqueteros/as asignaban a sus organizaciones. En este enfoque, la contraprestación laboral era valiosa en la medida en que ayuda a organizar la cotidianeidad de los/as desocupados/as, a obligarlos/as a salir de su casa. Sin embargo, se introduce en esta caracterización una distinción de género: mientras en el caso del varón la obligación de salir de su casa es presentado casi como un resguardo frente al abandono de sí al que lleva el desempleo, en el caso de las mujeres se plantea como un modo de ayudarla a ir más allá de las actividades domésticas, del cuidado de la propia familia. Así, la contraprestación es una alternativa a la chatura y la vagancia del varón y del confinamiento en el espacio doméstico de las mujeres.

Otro aspecto que se destaca en este testimonio es la idea de la irreversibilidad de los cambios que propicia la apertura de este espacio comunitario, que a la vez contiene pero supera el ámbito de la reproducción. Porque la concienciación femenina supone derechos y obligaciones diferentes a los que plantean los enfoques marxistas o

\footnotetext{
${ }^{13}$ En este sentido es necesario recordar que el Plan Jefes y Jefas de Hogar era administrado por el MTESS.
} 
feministas tradicionales Temma Kaplan (1990). No se trata de dejar de lado el espacio privado, sino de integrarlo inclusive como sentido de la propia movilización. Esto nos lleva a la tercera cuestión que plantea este testimonio y es la crítica al criterio de inempleabilidad femenina. Según este testimonio, no se trata de que las mujeres deban optar entre "vacunar al hijo o ir al comedor" sino de buscar modo de gestión del tiempo que permita compatibilizar ambos tipos de obligaciones que no pueden ser separadas sino desde un enfoque externo y ajeno a la vida cotidiana de estas mujeres.

\section{Reflexiones}

Si bien las comparaciones entre épocas y espacios, así como el trabajo interdisciplinario obligan a realizar un mayor esfuerzo para el análisis, justificaciones más elaboradas y a negociar determinadas miradas o estilos, también es cierto que este tipo de trabajo, de alguna manera, permite recuperar ciertos procesos y observar fenómenos en paralelo. Asimismo, somos conscientes de que Tucumán y Buenos Aires son dos provincias absolutamente distintas. Tanto económica, como social y políticamente son complejas y esquivas para las comparaciones. En ese sentido, en el preludio de este relato, los años treinta, ambas estaban, estadísticamente, en las antípodas. Posteriormente siguieron derroteros tan distintos como distantes. Sin embargo, a pesar de esas profundas diferencias, pudimos observar que las sensaciones colectivas de sus sectores populares, pero especialmente de sus mujeres, tenían un matiz muy similar, frente a diferentes respuestas del Estado en épocas y lugares distintos.

Una pauta común transversal resulta la tensión entre los roles asignados genéricamente y las necesidad de supervivencia en épocas críticas. Como han demostrado investigaciones previas, pero también ha sido observado en otros contextos por Kaplan (1990), las crisis sociales que afectan la reproducción son ámbitos interesantes porque si bien son sumamente propicios para la concienciación femenina, también lo son para el refuerzo de los estereotipos tradicionales. Ambos extremos, sin embargo, dan cuenta de una misma cosa, en contextos de crisis el rol de las mujeres suele modificarse y esos cambios suelen ser trascendentes y, en su mayoría, irreversibles.

En un universo social donde el trabajo tenía una centralidad muy arraigada y donde, aun cuando el quiebre de los modelos de organización centrados en el empleo se habían asentado con profundidad, los y las actores/as seguían reconociendo al trabajo como nodal. Y a pesar de que a las mujeres les estaba frecuentemente dificultado el acceso a la esfera laboral, fue justamente en ese tenso campo de fuerzas entre el deseo y el rol asignado, donde aparece la búsqueda de lugares de refugio para la crisis y las formas femeninas de acomodarse a los nuevos escenarios de profundo desempleo. Esas búsquedas y sus resultados o consecuencias en ambas épocas desdibujan las divisiones tajantes entre actividades remuneradas y no remuneradas y disuelven o permeabilizan las fronteras impuestas a las mujeres.

Así, en contextos críticos las mujeres se constituyeron en protagonistas que trabajaron para garantizar la supervivencia familiar, pero también y fundamentalmente en el espacio comunitario, a partir de su faena en comedores, roperos, cooperativas de compras, ollas populares o en la disputa por la baja de precios y en una huelga por mejores salarios. El barrio y el hogar constituyeron en tiempos de crisis no solo espacios de "domesticidad extradoméstica", sino que se revelaron como escenarios que permitieron a las mujeres salir de sus hogares y conformarse como sujetos públicos utilizando para ello sus saberes y conocimientos domésticos. En ese ir y venir, en esas labores de lucha, de resistencia y de solidaridad, el trabajo comunitario politizó sus 
habilidades, en tanto sus espacios de acción se entrelazaron con estrategias y negociaciones políticas. En sus itinerarios en los espacios públicos también politizaron sus cuerpos y su cotidianeidad y esto resultó una novedad sobre su vida y sus experiencias. En momentos donde la supervivencia está en juego, es imposible pensar la lucha cotidiana como ajena a una disputa política mayor.

Otra característica transversal es que estas mujeres suelen moverse fuera de los espacios institucionalizados de acción colectiva, o por lo menos fuera de los tradicionales de base clasista o partidaria. Los escenarios de crisis abren nuevos lugares de sociabilidad y lucha que se consolidan como fundamentales para las mujeres, siempre marginadas de los espacios más clásicos de construcción política como el partido o el sindicato. Sin embargo, ellas no son ajenas a los discursos circulantes, sino absolutamente permeables a esos nuevos sentidos con los cuales vinculan su labor cotidiana.

El hogar siempre constituyó un bastión de defensa, quizás el último o el único innegociable. Pero la evidencia sugiere o habilita a pensar que es posible que estas mujeres intervengan por razones que trascienden lo meramente económico. Hay algo fundamental en la supervivencia, pero hay también un deseo de trascender los espacios asignados. Una vez logrado, en esos lugares de refugio y de solidaridad ellas construyeron lazos afectivos, priorizaron la supervivencia y las necesidades de la vida diaria por sobre las luchas más tradicionales y crearon con ello su propio espacio de acción colectiva y movilización integrando sus esferas. En ese proceso transformaron sus valores, sus deseos y quebraron, sin romper, pero de manera casi irreversible, sus roles asignados.

En definitiva, es posible pensar las crisis como disruptivas de los roles asignados, circunstancias que abren intersticios por donde de alguna manera, entre la desesperación y la necesidad, las mujeres encuentran espacios para quebrar o desarmar sus obligaciones y extender su campo de acción hacia un afuera que, aunque no se extiende a los espacios clásicos de producción, constituyen escenarios extradomésticos.

En este trabajo nos aproximamos a las estrategias de y para las mujeres de los sectores populares u obreros en épocas de crisis en provincias diferentes y con metodologías diversas. Nuestro enfoque intentó desarticular o abandonar la clásica dicotomía públicoprivado, remunerado-no remunerado como compartimentos estancos y nos interesaba ver las estrategias de estas mujeres, sus espacios de acción y sus formas de constituirse como sujetos sociales en sus complejas trayectorias. Trayectorias que están inscriptas en el marco de las definiciones de la cuestión social en los distintos momentos analizados. En ese sentido, para seguir trabajando es importante tener en cuenta desde donde partimos para pensar las formas de inclusión-exclusión o de ciudadanía y exclusión. La ciudadanía puede ser contradictoria y los cruzamientos de género y clase pueden excluirse, pero también pueden funcionar como disparadores de la propia y original práctica ciudadana.

Bibliografía

ACHA, O (2000) "Catolicismo social y feminidad en la década del 30: de damas a mujeres"- Halperin P. y Acha O. (coords.) Cuerpos, géneros e identidades -Signo Buenos Aires.

ANDÚJAR, A (2007), "Pariendo resistencias: las piqueteros. Cutral Co y Plaza Huincul, 1996" - Bravo, M., GilLozano, F. y Pita, V. (comps) Historia de luchas, resistencias y representaciones, siglos $X I X y X X$-EDUNT-Tucumán. 
ARMSTRONG, N (1991). Deseo y ficción doméstica - Crítica - Crítica ASPIAZU, E (2013): "Trabajo y cuidado: la promoción de la justicia a través de políticas de conciliación con perspectiva de género" - Trabajo y Sociedad, Vol XVII, pp. 363-371

BAKER COLLINS, S (2005): "An understanding of poverty from those who are poor"Action Research, Vol 3, Na1, pp, 9-31

CASTEL, R (1997) Las metamorfosis de la cuestión social: una crónica del salariadoPaidós - Buenos Aires

CASTEL, R y HAROCHE, C (2001): Propriété privée, propriété sociale, propriété de soi, Fayard -Paris

CROSS, C (2013): "Vulnerabilidad social e inempleabilidad: Reflexiones a partir del estudio de un programa de reciclado de residuos sólidos urbanos" -Trabajo y Sociedad, Vol 17, No21, pp 475-494

CROSS, C y FREYTES FREY A (2007) "Movimientos piqueteros: Tensiones de género en la definición del liderazgo" - Argumentos, Vol 20, No 55, pp. 77-94.

D'ANTONIO D y ACHA, O (2000) "La clase obrera "invisible": imágenes y participación sindical de las obreras a mediados de la década de 1930 en Argentina"- En Halperin P. y Acha O. (coords.) Cuerpos, géneros e identidades- Signo - Buenos Aires. DANIEL, C (2009) "Las estadísticas laborales del Estado argentino (1910-1930). Controversias sociales, políticas y técnicas", en Workshop Elites intelectuales y formación del Estado- IDES/IDAES/UdeSA- Buenos Aires.

DANIEL, C (2013). "De crisis a crisis: la invención de la desocupación en la Argentina" -Revista de Indias, 73(257), 193-218.

DEPARTAMENTO NACIONAL DE TRABAJO (1933) La desocupación en la Argentina, 1932- Buenos Aires.

FORMICHELLA, M y LONDON, S (2013): "Empleabilidad, educación y equidad social" - Revista de Estudios Sociales, No47, pp 79-91

GAUTIÉ, J (2001) "De la invención del desempleo a su deconstrucción”, en Neffa, J.C., y Gautié, J (comp.), Desempleo y políticas de empleo en Europa y Estados Unidos LumenHumanitas - Buenos Aires.

GIRBAL-BLACHA, N (2003) "La Junta Nacional para combatir la desocupación. Tradición y modernización socioeconómica en los años’30” -Estudios del Trabajo, (25), enero-junio.

GLUCKSMANN, M (1995) "Why 'Work'. Gender and the Total Social Organization of Labour" - Gender, Work and Organization, Vol 2, No 2, 63-75, Abril.

JELIN, E. (1984) Familia y unidad doméstica: mundo público y vida privada -Estudios Cedes- Buenos Aires.

KAPLAN, T (1990) "Conciencia Femenina y Acción colectiva: el caso de Barcelona, 1910-1918”, - Amelang, J. Et al. Historia y Género. Las mujeres en la Europa Moderna y Contemporánea -Alfons El Magnánim-Valencia.

KOROL, J (2001) "La economía", en Cattaruzza, A. (dir.), Crisis económica, avance del Estado e incertidumbre política (1930-1943), Buenos Aires:Sudamericana

LOBATO, M (2007) Historia de las trabajadoras en la Argentina - Edhasa- Buenos Aires.

LOBATO, M (2008). "Trabajo, cultura y poder : dilemas historiográficos y estudios de género en Argentina." - Estudios de Filosofía Práctica e Historia de las Ideas, (10), 29 45 . 
NATERA RIVAS, J (2004) “Aglomerado San Miguel de Tucumán -Tafí Viejo (Argentina). Relación entre nivel de instrucción y mercado laboral en un contexto de crisis (1999/2002)" - Baetica: Estudios de Arte, Geografia e Historia, Vol 26, pp. 81102.

PANETTIERI, J (1996) "Paro forzoso y colocación obrera en Argentina en el marco de la crisis mundial (1929 -1934)"- La Plata, Cuadernos del CISH $\mathrm{N}^{\circ} 1$, primer semestre, pp. 9-30.

PANETTIERI, J (1997) "Crisis económica, perturbaciones en el mundo del trabajo y movimientos de población (1937-1943)" - Cuadernos del CISH, Año 2, No 2/3, UNLP, p. 49.

ROMO PARRA, C (2005): "Entre el látigo y la golosina. Reflexiones sobre la construcción de la disciplina temporal contemporánea en la esfera del trabajo remunerado"- Baetica: Estudios de Arte, Geografia e Historia, Vol 25, pp.523-541.

RIVAS, A y HERNÁNDEZ, C (2012) "Estructura agraria y pobreza: Consideraciones y aspecto de la ruralidad en la provincia de Tucumán (Argentina)"- Revista de Geografia (UFPE), Vol 29, $\mathrm{N}^{\circ} 1$, pp. 18-44

ROSANVALLON, P (1995) La Nueva Cuestión Social -Manantial- Buenos Aires SCOTT, J (2009), Género e Historia -FCE-México.

TAYLOR, B (1983): Eve and the New Jerusalem. Socialism and Feminism in the XIX Century - Pantheon Books-New York.

TUCCIO, L (2002) La mujer obrera argentina y su participación en las organizaciones sindicales entre 1930 y 1943 -Tesis de Licenciatura, Departamento de Historia, Facultad de Filosofía y Letras, Universidad de Buenos Aires.

RE, A (1937) El problema de la mendicidad en Buenos Aires -Biblioteca PolicialBuenos Aires. 